Jurnal REKSA: Rekayasa Keuangan, Syariah, dan Audit (Volume 5 No 1 Tahun 2018)

\title{
FAKTOR-FAKTOR PERSEPSI WAJIB PAJAK TERHADAP ETIKA PENGGELAPAN PAJAK
}

\author{
Wanda Surahman ${ }^{1)}$, Ulinnuha Yudiansa Putra ${ }^{2)}$ \\ ${ }^{1}$ Fakultas Ekonomi dan Bisnis Universitas Ahmad Dahlan Yogyakarta \\ email: wsurahman94@gmail.com \\ ${ }^{2}$ Fakultas Ekonomi dan Bisnis Universitas Ahmad Dahlan Yogyakarta \\ email: ulinnuha.yudiansa@act.uad.ac.id
}

\begin{abstract}
This study examines the effect of taxation understanding, subjective norm, love of money and religiousity on taxpayers' perception on tax evasion ethics. Primary data were obtained through direct survey using questionnaires. Using multiple regression analysis, four hypotheses were tested. The results show that only two hypotheses are supported revealing that taxation understanding and religiousity have positive effect on taxpayers' perception on tax evasion ethics.
\end{abstract}

Keywords: tax evation understanding, subjectiven norm, religiosity, love of money, taxpayer's perception ethic, tax evasion

\section{Latar Belakang}

Self assessment sistem merupakan salah satu pemungutan pajak yang diterapkan di Negara Indonesia. Self assesement system adalah suatu pemungutan pajak yang memberi wewenang, kepercayaan, tanggung jawab kepada wajb pajak untuk menghitung, memperhitungkan, membayar, dan melaporkan sendiri besarnya pajak yang harus dibayar. Penerapan sistem pemungutan pajak self assesment system akan efektif jika kondisi kesadaran wajib pajak terbentuk. Akan tetapi, data yang diungkapkan pada berita online tribbunnews.com menyatakan bahwa penerimaan pajak pada akhir tahun Indonesia diperkirakan hanya bisa mencapai kisaran 80\% $82 \%$, atau jauh di bawah target yang dibebankan dalam APBN-P sebesar Rp 1.294 triliun. Berita tersebut menyatakan bahwa kenyataan yang ada di Indonesia menunjukkan kesadaran wajib pajak terhadap pajak masih rendah atau dengan kata lain wajib pajak di Indonesia enggan untuk melaporkan/membayarkan pajaknya.

Terdapat berbagai macam faktor yang dapat mempengaruhi seseorang untuk melakukan suatu penggelapan pajak (tax evasion). Fuadi dan Yenni (2013) dalam Rahmawaty (2014), faktor yang mempengaruhi kepatuhan Wajib Pajak dapat berasal dari internal maupun eksternal. Faktor internal merupakan faktor yang berasal dari diri wajib pajak sendiri dan berhubungan dengan karakteristik individu yang menjadi pemicu dalam menjalankan kewajiban perpajakannya. Berbagai macam faktor internal yang dapat mempengaruhi seseorang terhadap suatu tindakan penggelapan pajak antara lain pemahaman pajak (Mutia, 2014), love of money (Basri, 2015). Tang dalam Hafizhah (2016) menyatakan bahwa cinta uang (love of money) mempunyai pengaruh pada perilaku yang tidak etis. Orang yang mencintai uang sangat tinggi cenderung tidak akan mau mengeluarkan uang untuk sesuatu yang tidak memberikan imbal balik kepadanya. Oleh karena itu, hal ini menimbulkan keinginan pada diri wajib pajak untuk melakukan kecurangan pajak, baik dengan tidak membayar pajak ataupun melaporkan pajak dengan nilai yang tidak benar.

Faktor eksternal adalah faktor yang berasal dari luar diri wajib pajak, misal situasi dan norma subjektif. Kewajiban untuk membayar wajib dipengaruhi oleh niat individu untuk membayar pajaknya atau tidak. Norma subjektif adalah keyakinan individu terhadap harapan normatif individu atau orang lain yang menjadi referensinya. Sehingga, individu tersebut akan melakukan 
suatu ketika individu yang yang menjadi referensinya menyetujuinya serta individu tersebut akan melakukan suatu tindakan karena termotivasi dari individu yang menjadi referensinya (Wanarta dan Mangoting, 2014). Faktor lain yang dapat mempengaruhi perilaku etis individu adalah religuisitas. Sikap religuitas diyakini sebagai penghalang perilaku tidak etis atau pembentukan moral yang baik. Religuitas berlaku seperti sebuah penegakan aturan-aturan yang dapat membatasi niatan individu atau wajib pajak untuk melakukan penggelapan pajak. Oleh karena itu, semakin tinggi tingkat religiusitas seseorang maka orang tersebut memiliki kecenderungan untuk menghindari penggelapan pajak.

\section{Kajian Literatur}

\section{Teori Pajak}

Menurut Prof. Dr. P.J.A Adriani dalam Resmi (2014), Pajak merupakan iuran kepada negara (yang dapat dipaksa) yang terhutang oleh yang wajib membayarnya menurut peraturanperaturan, dengan tidak mendapatkan prestasi kembali, yang langsung dapat ditunjuk, dan gunanya adalah untuk membiayai pengeluaran-pengeluaran umum terkait dengan tugas negara untuk menyelenggarakan pemerintah. Sedangkan, menurut Undang-undang Nomor 16 Tahun 2009, pajak didefinisikan sebagai kontribusi wajib kepada negara yang terutang oleh pribadi atau badan yang bersifat memaksa berdasarkan Undang-undang dengan tidak mendapatkan imbalan secara langsung dan digunakan untuk keperluan negara bagi sebesar-besarnya kemakmuran rakyat.

\section{Etika}

Pengertian Etika secara etimologi kata etika berasal dari bahasa Yunani yaitu "Ethos" yang berarti watak kesusilaan atau adat kebiasaan. Etika biasanya berkaitan erat dengan moral yang merupakan istilah dari bahasa latin, yaitu "mos" yang dalam bentuk melakukan perbuatan baik dan menghindari hal-hal tindakan yang buruk.

\section{Tax Evasion}

Menurut Mardiasmo (2004), tax evasion merupakan usaha yang dilakukan oleh wajib pajak untuk meringankan beban pajak dengan cara melanggar undang-undang (menggelapkan pajak).

\section{Pemahaman Perpajakan}

Pemahaman akan peraturan perpajakan erat kaitannya dengan pembayaran pajak. Resmi (2009) mengatakan bahwa pengetahuan dan pemahaman akan peraturan perpajakan adalah proses wajib pajak memahami tentang perpajakan dan menerapkan pengetahuan itu untuk membayar pajak.

\section{Norma Subjektif}

Ajzen (1991) dalam Wanarta dan Mangoting (2014) norma subjektif mengarah pada tekanan sosial yang dipersepsikan untuk melaksanakan perilaku tertentu atau tidak. Norma subjektif terbentuk dari normative belief, yaitu keyakinan individu terhadap harapan normatif individu atau orang lain yang menjadi referensi/yang dianggap penting untuk menyetujui atau menolak melakukan suatu perilaku yang diberikan serta motivasi yang diberikan oleh orang-orang yang direferensikan tersebut kepada individu.

\section{Love of Money}

Love of money adalah suatu pengukuran terhadap nilai seseorang, atau keinginan akan uang akan tetapi bukan kebutuhan mereka dan makna atau pentingnya yang serta perilaku pada uang (Tang, 2004 dalam Azziz, 2015). Orang yang memiliki kecintaan pada uang yang begitu besar, orang tersebut akan menempatkan uang sebagai hal yang sangat penting. Oleh karena itu, orang mempunyai kecintaan yang sangat besar pada uang akan berperilaku kurang etis dibandingkan 
dengan orang yang mempunyai kecintaan pada uang yang lebih rendah (Tang (2002) dalam Basri (2015).

\section{Religiusitas}

Agama adalah salah satu Lembaga sosial yang paling universal yang memiliki pengaruh pada sikap masyarakat, nilai-nilai, dan perilaku baik pada tingkat individu maupun masyarakat. Keagamaan atau religiusitas diwujudkan dalam berbagai sisi kehidupan manusia (Mohlis, 2009 dalam Fauzan, 2015).

\section{Pengembangan Hipotesis}

\section{a. Pengaruh Pemahaman Perpajakan terhadap Penggelapan Pajak}

Pembayaran pajak sering dikaitkan dengan pemahaman seseorang pada peraturan pajak. Resmi (2009) menyatakan bahwa pengetahuan dan pemahaman pada peraturan perapajakan adalah proses wajib pajak memahami mengenai perpajakan dan menerapkan pengetahuan yang dimilikinya untuk membayar pajak. McGee (2009) dalam Wicaksono (2014) menyatakan bahwa wajib pajak yang memiliki pemahaman mengenai perpajakan yang baik akan cenderung menghindari suatu tindakan yang melanggar ketentuan perpajakan. Oleh karena itu, berdasarkan uraian sebelumnya, maka hipotesis pertama penelitian ini yaitu sebagai berikut.

H1: Pemahaman perpajakan berpengaruh terhadap persepsi wajib pajak mengenai etika penggelapan pajak.

\section{b. Pengaruh Norma Subjektif terhadap Penggelapan Pajak}

Hasil penelitian menunjukkan bahwa norma subjektif adalah faktor yang paling berpengaruh terhadap niat wajib pajak untuk berperilaku patuh. Pengaruh dari orang-orang sekitar serta motivasi yang diberikan oleh orang-orang sekitar atau orang-orang yang dianggap penting dan paling berpengaruh seperti keluarga, teman, rekan kerja, konsultan pajak, dan lain-lain dapat mempengaruhi niat dan perilaku seseorang/wajib pajak untuk patuh atau tidak (Mangoting dan Wanarta, 2014). Oleh karena itu, berdasarkan uraian sebelumnya, maka hipotesis kedua penelitian ini yaitu sebagai berikut.

H2: Norma subjektif berpengaruh terhadap persepsi wajib pajak mengenai etika penggelapan pajak.

\section{c. Pengaruh Love of Money terhadap Penggelapan Pajak}

Lau, Choe, dan Tan (2013) dalam Rosianti dan Mangoting (2014) menemukan adanya hubungan antara etika uang (love of money) dengan tax evasion. Ketika seseorang menekankan pada pentingnya uang dan memperoleh kekayaan, mereka akan merasa bahwa tax evasion dapat diterima. Seseorang yang sangat termotivasi oleh uang atau yang menempatkan uang sebagai prioritas utama akan percaya bahwa tax evasion adalah tindakan yang etis. Oleh karena itu, hipotesis ketiga penelitian ini yaitu sebagai berikut.

H3: love of money berpengaruh terhadap persepsi wajib pajak mengenai etika penggelapan pajak.

\section{d. Pengaruh Religiusitas terhadap Penggelapan Pajak}

Grasmick, Bursik, \& Cochran, (1991) dalam penelitian Basri (2015) menyatakan keyakinan agama yang kuat diharapkan mencegah perilaku ilegal melalui perasaan bersalah terutama dalam hal penghindaran pajak. Oleh karena itu, hipotesis keempat penelitian ini yaitu sebagai berikut.

H4: Religiusitas berpengaruh terhadap persepsi wajib pajak mengenai etika penggelapan pajak. 
Dari kajian literatur dan pengembangan hipotesis, maka rerangka penelitian ini dapat digambarkan sebagai berikut.

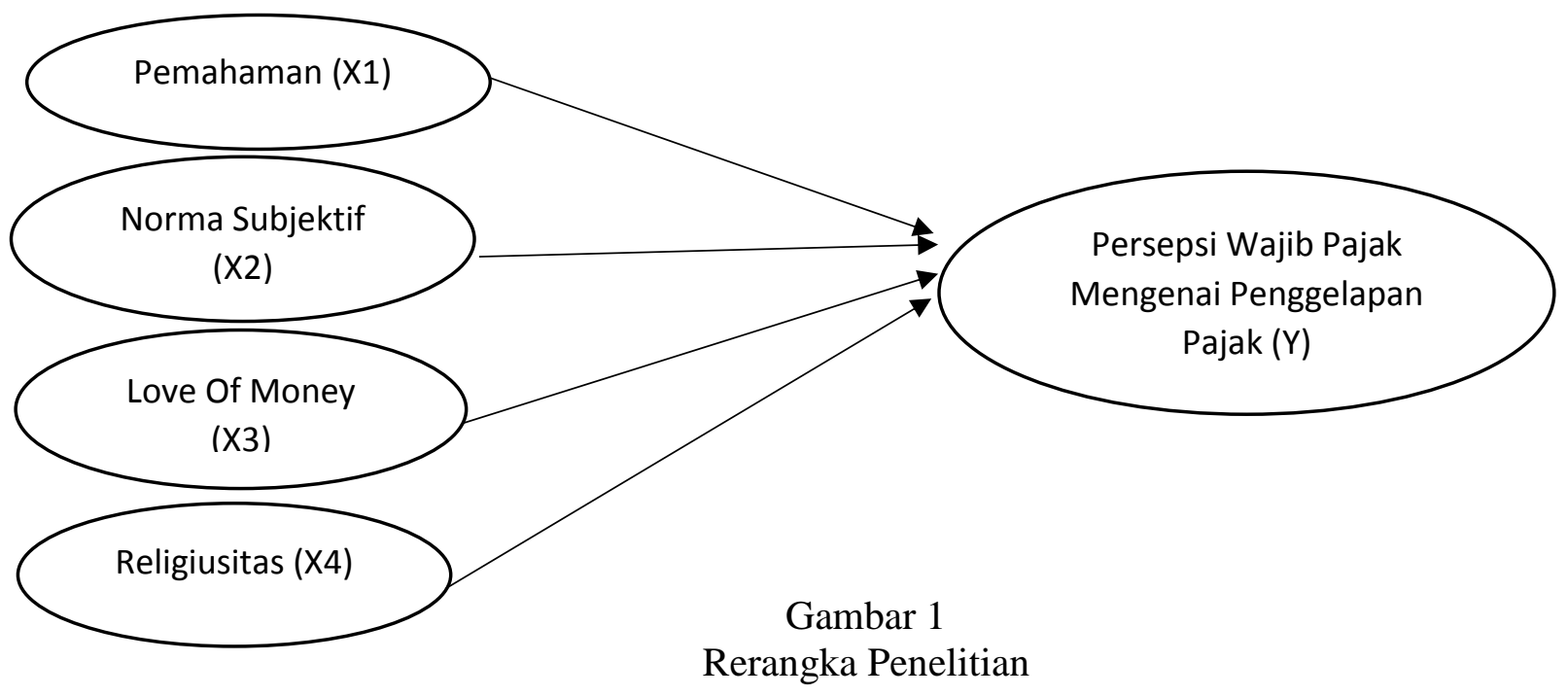

\section{Metoda Penelitian}

Populasi penelitian ini adalah pelaku Usaha Mikro Kecil dan Menengah. Pengambilan sampel dalam penelitian ini menggunakan convencience sampling, yaitu sampel yang dipilih berdasarkan pertimbangan kemudahan. Seseorang diambil sebagai sampel karena kebetulan orang tadi ada di situ atau kebetulan dia mengenal orang tersebut.

Pengujian hipotesis dalam penelitian menggunakan analisis regresi berganda. Sebelum pengujian hipotesis, penelitian terlebih dahulu menguji validitas, reliabilitas, dan asumsi klasik. Penelitian ini memenuhi uji validitas dan relibilitas. Uji asumsi klasik dalam penelitian meliputi uji normalitas, uji heterosdestasitas, dan uji multikolonieritas. Model regresi linear berganda yang digunakan adalah sebagai berikut:

$$
Y=a+\beta_{1} X_{1}+\beta_{2} X_{2}+\beta_{3} X_{3}+\beta_{4} X_{4}+e
$$

Keterangan:

$$
\begin{array}{ll}
\mathrm{Y} & =\text { Persepsi Wajib Pajak mengenai Etika penggelapan pajak } \\
\mathrm{a} & =\text { Konstanta } \\
X_{1} & =\text { Koefisien Regresi Pemahaman Pajak } \\
X_{2} & =\text { Koefisien Regresi Norma Subjektif } \\
X_{3} & =\text { Koefisien Regresi Love Of Money } \\
X_{4} & =\text { Koefisien Regresi Religiusitas } \\
\mathrm{e} & =\text { Error Term }
\end{array}
$$

Pengujian hipotesis dalam penelitian ini meliputi koefisien determinasi $\left(\mathrm{R}^{2}\right)$, Uji F, dan Uji. Koefisien determinasi $\left(\mathrm{R}^{2}\right)$ yang digunakan untuk mengetahui seberapa besar variabel independen yang digunakan pada penelitian ini dapat menjelaskan pengaruhnya terhadap variabel dependennya. Uji statistik F digunakan untuk mengetahui ada tidaknya hubungan secara bersama-sama variabel independen yang digunakan pada penelitian terhadap variabel dependen. Uji statistik t digunakan untuk melihat hubungan antar tiap variabel independen dengan variabel dependen-nya (Ghozali, 2016). 


\section{Hasil Penelitian dan Pembahasan}

Alat ukur yang digunakan dalam penelitian reliabel dan valid. Penelitian ini juga memenuhi uji asumsi klasik. Uji normalitas disajikan pada tabel 1. Tabel 1 menujukan bahwa data residual terdistribusi secara normal. Hal ini ditunjukan dengan nilai signifikasi $(0,102)$ lebih besar dari 0,05 (Ghozali, 2016:159).

\section{Tabel 1}

Hasil Uji Normalitas Data

\begin{tabular}{|c|c|c|}
\hline Keterangan & $\begin{array}{c}\text { Unstandardized } \\
\text { Residual }\end{array}$ & Alpha \\
\hline N & 100 & 0,05 \\
\hline Asymp. Sig. (2-tailed) & 0,102 & \\
\hline
\end{tabular}

\section{Sumber: data primer diolah (2017)}

Penelitian ini juga memenenuhi uji multikolinieritas. Hal ini dapat dilihat pada tabel 2. Tabel 2 menujukan bahwa Tolerance juga menunjukkan tidak ada variabel independen yang memiliki nilai Tolerance kurang dari 0.10 yang berarti tidak ada korelasi antara variabel independen yang nilainya lebih dari 95\%. Hasil perhitungan nilai Variance Inflation Factor (VIF) juga menunjukkan hal yang sama tidak ada satu variabel independen yang memiliki nilai VIF lebih dari 10. Jadi dapat disimpulkan bahwa tidak ada multikolinieritas ntara variabel independen dalam model regresi.

Tabel 2

Hasil Uji Multikolonieritas

\begin{tabular}{|l|c|c|c|}
\hline \multicolumn{1}{|c|}{ Variabel Independen } & Tolerance & VIF & Keterangan \\
\hline Pemahaman Perpajakan & 0,870 & 1,150 & $\begin{array}{c}\text { Tidak ada } \\
\text { multikolinieritas }\end{array}$ \\
\hline Norma Subjektif & 0,797 & 1,255 & $\begin{array}{c}\text { Tidak ada } \\
\text { multikolinieritas }\end{array}$ \\
\hline Love Of Money & 0,937 & 1,067 & $\begin{array}{c}\text { Tidak ada } \\
\text { multikolinieritas }\end{array}$ \\
\hline Religiusitas & 0,833 & 1,201 & $\begin{array}{c}\text { Tidak ada } \\
\text { multikolinieritas }\end{array}$ \\
\hline
\end{tabular}

Sumber: data primer diolah (2017)

Hasil uji heteroskedastisitas disajikan pada tabel 3. Uji heteroskedastisitas dalam penelitian ini menggunakan uji white. Berikut hasil uji heteroskedastisitas.

Tabel 3

Hasil Uji Heteroskedasitas

\begin{tabular}{|l|c|}
\hline \multicolumn{1}{|c|}{ Keterangan } & Sig. \\
\hline Pemahaman Perpajakan & 0,848 \\
\hline Norma Subjektif & 0,272 \\
\hline Love of Money & 0,807 \\
\hline Religiusitas & 0,244 \\
\hline
\end{tabular}

Sumber: data primer diolah (2017) 
Jurnal REKSA: Rekayasa Keuangan, Syariah, dan Audit (Volume 5 No 1 Tahun 2018)

Tabel 3 menunjukan bahwa hasil variabel independent (religisuitas) terbebas dari heteroskedasitas. Hal ini terlihat dari nilai signifikasi yang lebih besar dari 0,05.

\section{Hasil Uji Hipotesis}

\section{Hasil Analisis Regresi Linier Berganda}

Tabel 4 menyajikan hasil uji koefisien determinasi. Tabel 4 menunjukan bahwa penelitian ini memiliki nilai adjusted $R$-Square sebesar 0,349. Hal ini menunjukan bahwa variabel persepsi etika penggelapan pajak dapat sebesar 34,9\% dapat dijelaskan oleh variabel pemahaman pajak, norma subjektif, love of money, dan religiusitas.

\section{Tabel 4}

Koefisien Determinasi

\begin{tabular}{|c|c|c|c|}
\hline $\mathbf{R}$ & R Square & $\begin{array}{c}\text { Adjusted R } \\
\text { Square }\end{array}$ & $\begin{array}{c}\text { Std. Error of } \\
\text { the Estimate }\end{array}$ \\
\hline $0,612^{\mathrm{a}}$ & 0,375 & 0,349 & 9,986 \\
\hline
\end{tabular}

\section{Sumber: data primer diolah (2017)}

Pengujian signifikansi $\mathrm{F}$ bertujuan untuk mengetahui ada tidaknya pengaruh variabel independen terhadap variabel dependen dalam model penelitian ini (Ghozali, 2016). Hasil pengujian signifikansi $\mathrm{F}$ menunjukkan hasil regresi diperoleh niali signifikansi (F-Statistic) sebesar 14,240. Nilai signifikansi (F-statistic) 14,240 > 0,05 (alpha). Oleh karena itu, dapat diambil kesimpulan bahwa variabel independen yang terdiri dari pemahaman perpajakan, norma subjektif, love of money, dan religiusitas mempunyai pengaruh terhadap persepsi wajib pajak mengenai etika penggelapan pajak (tax evasion).

\section{Tabel 5}

Hasil Uji t

\begin{tabular}{|c|l|c|c|c|c|}
\hline No. & \multicolumn{1}{|c|}{ Variabel } & Koefesien & T & Sig. & Keterangan \\
\hline 1 & $\begin{array}{l}\text { Pemahaman } \\
\text { Perpajakan }\end{array}$ & 0,275 & 3,165 & 0,002 & $\mathrm{H}_{1}$ didukung \\
\hline 2 & Norma Subjektif & $-0,085$ &,- 931 & 0,354 & $\mathrm{H}_{2}$ tidak dapat didukung \\
\hline 3 & Love of Money & 0,048 &, 568 & 0,571 & $\mathrm{H}_{3}$ tidak dapat didukung \\
\hline 4 & Religiusitas & 0,519 & 5,838 & 0,000 & $\mathrm{H}_{4}$ didukung \\
\hline
\end{tabular}

Sumber: data primer diolah (2017)

Tabel 5 menujukan hasil uji t. Berdasarkan hasil uji t dalam tabel 5 yang menunjukkan bahwa pemahaman perpajakan memiliki nilai signifikasi sebesar 0,002. Nilai tersebut lebih kecil dari pada alpha $(0,05)$, artinya hipotesis pertama diterima. Hal ini berarti pemahaman pajak berpengaruh terhadap persepsi wajib pajak mengenai penggelapan pajak. Hal ini dapat dijelaskan bahwa tingkat pemahaman adalah suatu proses peningkatan pengetahuan secara intensif yang dilakukan seseorang individu dan sejauh mana seseorang dapat mengerti dengan benar akan suatu permasalahan yang ingin diketahui. Tingkat pemahaman wajib pajak mengenai perpajakan merupakan faktor potensial bagi pemerintah untuk meningkatkan kepatuhan wajib pajak. Dengan tingkat pemahaman yang baik seseorang akan dapat melaksanakan sesuatu dengan baik pula. Dalam menjalankan kewajiban perpajakannya, wajib pajak haruslah menguasai peraturan serta kewajiban yang dijalankannya agar terhindar dari sanksi-sanksi yang berlaku. Dengan demikian pemahaman tentang perpajakan berupa sistem perpajakan dan peraturan perpajakan akan mencegah wajib pajak melakukan tindakan penggelapan pajak (tax evasion) dalam membayar kewajibannya terhadap perpajakan. 
Varibel norma subjektif memiliki nilai signifikasi sebesar 0,354. Nilai tersebut lebih besar dari pada alpha $(0,05)$, artinya hipotesis kedua ditolak. Hal ini bearti bahwa norma subjektif tidak berpengaruh terhadap persepsi wajib pajak mengenai penggelapan pajak. Hasil ini dapat menjelaskan bahwa bahwa lingkungan sosial yang meliputi keluarga, teman, konsultan pajak, petugas pajak, serta media cetak dan media elektronik belum bisa memengaruhi wajib pajak untuk berniat patuh terhadap pajak. Dalam planned behavior theory, norma subjektif ditentukan oleh kombinasi antara belief individu tentang kesetujuan dan atau ketidaksetujuan seseorang maupun kelompok yang penting bagi individu terhadap suatu perilaku (normative beliefs), dengan motivasi individu untuk mematuhi rujukan tersebut (motivation to comply). Motivation to comply sebagai salah satu hal yang memengaruhi nilai norma subjektif tentang suatu perilaku adalah dipengaruhi oleh kekuatan sosial. Kekuatan sosial yang dimaksud terdiri dari penghargaan atau hukuman yang diberikan sumber rujukan kepada individu. Kemungkinan norma subjektif tidak berpengaruh terhadap penggelapan pajak dikarenakan kekuatan sosial yang rendah. Kekuatan sosial yang rendah dimaksud jika wajib pajak melakukan pembayaran pajak apa yang akan diperoleh atau keuntungan yang diberikan pemerintah kepada wajib pajak.

Variabel love of money memiliki nilai signifikasi sebesar 0,571, artinya hipotesis ketiga ditolak. Hasil penelitian menunjukkan bahwa love of money tidak berpengaruh terhadap persepsi wajib pajak mengenai etika penggelapan pajak (tax evasion). Hal ini dapat dijelaskan bahwa sikap love of money tidak memandang kondisi untuk wajib pajak melakukan tindakan tidak etis atau melakukan kecurangan pajak (tax evasion). Ketidakterdukungan hipotesis ketiga mungkin disebabkan adanya faktor lain yang dapat mempengaruh persepsi etika penggalapan pajak, yaitu kontrol keperilakuan. Kontrol keperilakuan adalah sejumlah kontrol yang diyakini akan mendorong Wajib Pajak dalam menampilkan perilaku kepatuhan pajak. Kontrol keperilakuan dapat mempengaruhi perilaku baik itu secara langsung maupun tidak langsung.

Variabel religiusitas memiliki nilai signifikasi sebesar 0,000. Nilai tersebut lebih kecil dari pada alpha $(0,05)$, artinya hipotesis diterima. Hal ini berari bahwa religiusitas mempunyai pengaruh pada pesepsi wajib pajak mengenai pengelapan pajak. Hal ini dapat dijelaskan bahwa Sikap religiusitas yang ada dalam diri seseorang dapat mengendalikan setiap perbuatan yang dilakukannya. Di dalam agama, perbuatan penggelapan pajak adalah perbuatan yang tidak benar sehingga dengan alasan apapun seseorang tidak akan melakukan penggelapan pajak karena seseorang menjadikan agama sebagai driving integrating motive yang mengatur seluruh hidupnya.

\section{Simpulan dan Saran}

Penelitian ini bertujuan untuk mengetahui bahwa pemahaman perpajakan, norma subjektif, love of money dan religiusitas kecurangan terhadap persepsi wajib pajak mengenai etika penggelapan pajak. Responden penelitian ini berjumlah 100 pelaku UMKM pada wilayah Yogyakarta.

Pemahaman perpajakan berpengaruh terhadap persepsi wajib pajak mengenai etika penggelapan pajak (tax evasion). Hasil penelitian memberikan bukti empiris bahwa ingkat pemahaman yang baik seseorang akan dapat melaksanakan sesuatu dengan baik pula. Dalam menjalankan kewajiban perpajakannya, wajib pajak haruslah menguasai peraturan serta kewajiban yang dijalankannya agar terhindar dari sanksi-sanksi yang berlaku. Dengan demikian pemahaman perpajakan berupa informasi perpajakan dan peraturan perpajakan akan mencegah wajib pajak melakukan tindakan penggelapan pajak.

Norma subjektif tidak berpengaruh terhadap persepsi wajib pajak mengenai etika penggelapan pajak (tax evasion). Hasil penelitian menjelaskan bahwa lingkungan sosial yang 
meliputi keluarga, teman, konsultan pajak, petugas pajak, serta media cetak dan media elektronik belum bisa memengaruhi wajib pajak untuk berniat patuh terhadap pajak.

Love of money tidak berpengaruh terhadap persepsi wajib pajak mengenai etika penggelapan pajak (tax evasion). Hasil ini menjelaskan kontrol keprilakuan atau sikap yang religiusitas kemungkinan mencegah sikap love of money untuk tidak melakukan tindakan penggelapan pajak.

Religiusitas berpengaruh terhadap berpengaruh terhadap persepsi wajib pajak mengenai etika penggelapan pajak (tax evasion). Hasil ini menjelaskan bahwa jika religiusitas tinggi keyakinan yang kuat pada agama mengurangi sikap untuk melakukan kecurangan pajak.

\section{Referensi}

Alvin, Aloysius. 2014. Pengaruh Sikap, Norma Subyektif, dan Kontrol Perilaku yang Dipersepsikan Staff Pajak Terhadap Kepatuhan Pajak Wajib Pajak badan. Jurnal. Surabaya [online].

Didapatkan: http://download.portalgaruda.org/article.php?article=336678\&val=6512\&title=PENGARU H\%20SIKAP,\%20NORMA\%20SUBYEKTIF,\%20DAN\%20KONTROL\%20PERILAKU \%20YANG\%20DIPERSEPSIKAN\%20STAFF\%20PAJAK\%20TERHADAP\%20KEPAT UHAN\%20PAJAK\%20WAJIB\%20PAJAK\%20BADAN [9 desember 2016].

Azziz, Toriq Ibnu. (2015). "Pengaruh Love Of Money dan Machiavellian Terhadap Persepsi Etis Mahasiswa Akuntansi”. Skripsi. Universitas Negeri Yogyakarta [online]. Didapatkan: http://eprints.uny.ac.id/28887/1/SKRIPSI\%20FULL.pdf [3 Mei 2017].

Basri, Yesi Mutia. 2014. Efek Moderasi Religuisitas dan Gender Terhadap Hubungan Etika Uang ( Love Of Money) dan Kecurangan Pajak (Tax Evasion). Jurnal. Riau. Universitas Riau [online]. Didapatkan: https://ojs.unud.ac.id/index.php/jiab/article/view/16818/11086 [9 Maret 2016].

Basri, Yesi Mutia. 2015. Pengaruh Dimensi Budaya dan Religuitas Terhadap Kecurangan Pajak. Jurnal. Riau. Universitas Riau [online]. Didapatkan: http://download.portalgaruda.org/article.php?article=437540\&val=337\&title=PENGARU H\%20DIMENSI\%20BUDAYA\%20DAN\%20RELIGIUSITAS\%20TERHADAP\%20KEC URANGAN\%20PAJAK [19 Maret 2016].

Basri, Yesi Mutia. 2015. Pengaruh Gender, Religuitas dan Love Of Money Pada Persepsi Etika Penggelapan Pajak Mahasiswa Akuntansi. Tesis. Riau. Universitas Riau [online]. Didapatkan: https://ojs.unud.ac.id/index.php/jiab/article/download/16818/11086/ [17 April 2016].

Bidin, Zainol and Shamsudin, Faridahwati Mohd. (2013). "Using Theory of Reasoned Action to Explain Taxpayer Intention to Comply with Goods and Services Tax (GST)”. 06010 Sintok, Kedah, Malaysia. University Utara Malaysia [online]. Didapatkan: https://www.idosi.org/mejsr/mejsr17(3)13/20.pdf [27 Mei 2016].

Fauzan. 2015. Pengaruh Religuitas dan Ethical Climate Terhadap Ethical Behavior. Jurnal. Malang. Universitas Kajuruhan [online]. Didapatkan: http://ejournal.unikama.ac.id/index.php/JEKO/article/view/1095 [7 April 2016].

Ghozali, Imam. 2016. “Aplikasi Analisis Multivariate Dengan Program IBM SPSS 23, Edisi 8 ”. Semarang: Universitas Diponegoro. 
Jurnal REKSA: Rekayasa Keuangan, Syariah, dan Audit (Volume 5 No 1 Tahun 2018)

Hafizhah, Ihsanul. 2016. "Pengaruh Etika Uang (Money Ethics) Terhadap Kecurangan Pajak (Tax Evasion) Dengan Religuitas, Gender, dan Materialisme Sebagai Variable Moderasi”. Jurnal. Riau. Universitas Riau [online]. Didapatkan: http://jom.unri.ac.id/index.php/JOMFEKON/article/viewFile/11770/11418 $[7$ Oktober 2016].

Indriantoro, N., \& Bambang, S. (2014). Metodologi Penelitian Bisnis Untuk Akuntansi dan Manajemen (edisi 1). Yogyakarta: BPFE.

Izza, Nur Ika Alfi dan Hamzah, Ardi. "Etika Penggelapan Pajak Perspektif Agama: Sebuah Studi Interpretatif ". Jurnal. Surabaya [online]. Didapatkan: https://smartaccounting.files.wordpress.com/2011/03/etika-penggelapan-pajak-perspektifagama-sebuah-studi-interpretatif.pdf [10 Maret 2016].

Liberti, Pandiangan. 2014. Administrasi Perpajakan. Jakarta: Penerbit Erlangga.

Mardiasmo. 2004. Perpajakan. Yogyakarta: Andi Yogyakarta.

Marsyahrul, Tony. 2005. Pengantar Perpajakan.Jakarta: PT Grasindo.

Mutia, Sri Putri Tita. (2014). "Pengaruh Sanksi Perpajakan, Kesadaran Perpajakn, Pelayanan Fiskus, dan Tingkat Pemahaman Terhadap Kepatuahan Wajib Pajak Orang Pribadi”. Jurnal. Universitas Negeri Padang [online]. Didapatkan: http://ejournal.unp.ac.id/students/index.php/akt/article/view/902 [7 Desember 2016].

Oktaviani, Rachmawati Meita. 2015. Determinan Kepatuhan Wajib Pajak Badan Dengan Niat Sebagai Pemedasi Dari Perspektif Planned. Jurnal. Universitas Stikubank Semarang [online]. Didapatkan: https://media.neliti.com/media/publications/24218-ID-determinankepatuhan-wajib-pajak-badan-dengan-niat-sebagai-pemediasi-dari-perspe.pdf $[22$ Mei 2017].

Pramudito, Sigit Priadi. <http://wartakota.tribunnews.com/2015/12/02/inilah-penyebab-dirjenpajak-mengundurkan-diri>. Diunduh [September 2016].

Rahmawaty, Stella. 2014. Pengaruh Pengetahuan, Modernisasi Strategi Direktoral Jenderal Pajak, Sanksi Perpajakan dan Religiusitas Yang Dipersepsikan Terhadap Kepatuhan Perpajakan. Jurnal. Malang. Universitas Brawijaya [online]. Didapatkan: http://download.portalgaruda.org/article.php?article=274096\&val=6467\&title=Pengaruh\% 20Pengetahuan [7 April 2016].

Ramdhani, Neila. Didapatkan: http://neila.staff.ugm.ac.id/wordpress/?p=147. [31 Mei 2017].

Resmi, Siti. 2014. Perpajakan: Teori dan Kasus. Yogyakarta. Penerbit Salemba Empat.

Ridwan, Ahmad. 2014. Sensitivitas Etika Wajib Pajak Atas Tax Evasion. Jurnal. Surakarta. Jawa Tengah. Universitas Sebelas Maret Surakarta [online]. Didapatkan: https://digilib.uns.ac.id/dokumen/detail/37493/Sensitivitas-Persepsi-Wajib-Pajak-BadanAtas-Tax-Evasion-Studi-Kasus-Di-Kantor-Pelayanan-Pajak-Pratama-Surakarta [ 9 Maret 2016].

Rosianti, Camelia dan Mangoting, Yenny. 2014. Pengaruh Money Ethics terhadap Tax Evasion dengan Intrinsic dan Extrinsic Religiosity sebagai Variabel Moderating. Jurnal. Universitas Kristen Petra [online]. http://download.portalgaruda.org/article.php?article $=336705 \&$ val=6512\&title=Pengaruh $\%$ 20Money $\% 20$ Ethics $\% 20$ terhadap $\% 20$ Tax $\% 20$ Evasion $\% 20$ dengan $\% 20$ Intrinsic $\% 20$ dan $\% 2$ 0Extrinsic\%20Religiosity\%20sebagai\%20Variabel\%20Moderating [11 April 2016].

Sambodo, Agus. 2015. Pajak Dalam Entitas Bisnis. Jakarta: Salemba Empat.

Sugiyono. 2011. Metode Penelitian Bisnis. Bandung: CV Alfabeta. 
Jurnal REKSA: Rekayasa Keuangan, Syariah, dan Audit (Volume 5 No 1 Tahun 2018)

Syahril, Farid. 2013. Pengaruh Tingkat Pemahaman Wajib Pajak dan Kualitas Pelayanan Fiskus Terhadap Tingkat Kepatuhan Wajib Pajak PPh Orang Pribadi. Skripsi. Universitas Negeri Padang. Diunduh http://ejournal.unp.ac.id/students/index.php/akt/article/view/639 [29 Mei 2017].

Tribun.com

Undang-undang Nomor 16 Tahun 2009 Tentang Ketentuan Umum dan Tata Cara Perpajakan Waluyo. 2011. Perpajakan Indonesia. Jakarta: Salemba Empat.

Wanarta, Feby Eileen dan Mangoting, Yenny. 2014. Pengaruh Sikap Ketidakpatuhan Pajak, Norma Subjektif, dan Kontrol Perilaku yang Dipersepsikan terhadap Niat Wajib Pajak Orang Pribadi untuk Melakukan Penggelapan Pajak. Jurnal. Universitas Kristen Petra [online].

Didapatkan:

http://download.portalgaruda.org/article.php?article $=336725 \& v a l=6512 \&$ title $=$ Pengaruh $\%$ 20Sikap\%20Ketidakpatuhan\%20Pajak,\%20Norma\%20Subjektif,\%20dan\%20Kontrol\%20 Perilaku\%20yang\%20Dipersepsikan\%20terhadap\%20Niat\%20Wajib\%20Pajak\%20Orang \%20Pribadi\%20untuk\%20Melakukan\%20Penggelapan\%20Pajak [9 Desember 2016].

Wicaksono, Muhammad Ary. 2014. Pengaruh Persepsi Sistem Perpajakan, Keadilan Pajak, Diskriminasi Pajak dan Pemahaman Perpajakan Terhadap Perilaku Penggelapan Pajak. Semarang. Universitas Diponegoro [online]. Didapatkan: http://eprints.undip.ac.id/45118/1/06_WICAKSONO.pdf [5 Desember 2016]. 